\title{
Criação de narrativa num cartaz através de animação
}

João Ribeiro

\author{
Escola Superior de Media Artes e Design do Instituto Politécnico do Porto, Portugal \\ Vítor Quelhas
}

Escola Superior de Media Artes e Design do Instituto Politécnico do Porto, ID+ / uniMAD, Portugal

\begin{abstract}
Gamblers never win is a small series of augmented reality animated posters with the purpose of revealing a narrative to the viewer, dividing the poster into two parts, a visual pun and the textual information. Focused on the theme of gambling addiction, and with an informative function, the posters make use of illustration and text compositions with contrasting colours and a particular minimal aesthetic in order to capture the attention of the passer- by. The contrasting colours also help the algorithm identify what animation to be reproduced depending on what poster is being seen. The project raises some questions such as the usefulness of an animated poster, what are the means available for exhibition, in which ways does it evolve from a static poster, what differentiates an animated poster from a video, will the static poster become obsolete, among others.
\end{abstract}

Keywords: Poster, Design, Animation, Augmented Reality, Gambling

\section{Introdução}

De acordo com o briefing de Projeto de Design Pessoal (Projeto I) do $1 .^{\circ}$ ano do Mestrado em Design da Escola Superior de Media Artes e Design do Instituto Politécnico do Porto, os estudantes são propostos a realizar um projeto de investigação exploratória incentivado por uma área temática suscitada pela visita ao Arquivo Municipal da Póvoa de Varzim.

Decidiu-se abordar o tema do vício no jogo, utilizando como meio de comunicação e exploração, o cartaz animado. Considerou-se relevante investigar de forma exploratória, como um componente do multimédia atualmente em crescimento - a animação - se pode aliar ao design, procurando salientar através deste projeto a inovação tecnológica e as suas vantagens, mas não esquecendo também os fatores socioculturais que os novos meios e dispositivos têm adicionado à nossa vida em sociedade. A animação pode ser utilizada no sentido de potenciar a comunicação através, por exemplo, da expressão e transmissão de ideias em movimento.

Nesta comunicação contextualizar-se-á o processo de pesquisa e construção dos cartazes, assim como algumas reflexões conclusivas em relação ao cartaz animado, realidade aumentada e a relevância de ambos num contexto de divulgação de informação.
(...) the designer's experiments have taught us that it would be enough to employ an unusual colour, a different form, and to give the passer-by exact and immediate information instead of assaulting him time and time again until he is battered senseless (Munari 2008, 85).

\section{Percurso}

Foram efetuadas várias visitas ao Arquivo Municipal da Póvoa de Varzim e realizadas pesquisas pelos documentos encontrados no catálogo disponível para consulta pública. Em busca de inspiração na imagética conservada no espaço, foram encontrados e analisados um conjunto de documentos, como registos de movimentos financeiros e publicitários, referentes ao casino da Póvoa de Varzim.

Sendo um dos primeiros casinos em Portugal, surge numa cidade em crescimento onde os cidadãos se deparam com um edifício construído única e exclusivamente para atividades de lazer, desde comida e espetáculos a "jogos de sorte e azar" (Martine 2012).

Inicialmente efetuou-se uma pesquisa relacionada com os modelos de gestão de casinos, numa tentativa de se perceber como os mesmos lucram. Nessa mesma pesquisa surgiu o conceito de house edge. House edge consiste numa percentagem do montante financeiro apostado que é salvaguardada pelo casino, fazendo com que o mesmo, a longo prazo, acabe sempre por beneficiar, uma vez que tem, estatisticamente, uma probabilidade maior de ganhar do que o jogador (Bluejay 2018).

No seguimento da descoberta do tema, tomou-se curiosidade em perceber até que ponto o jogo pode levar um indivíduo a situações limite, na esperança de ganhar ao casino. Foi visualizado um documentário, denominado "Gambling Addiction \& Me: The Real Hustler", de Alexis Conran. Este documentário mostrou um lado mais sombrio do casino, particularmente o vício do jogo e as consequências do mesmo.

Numa altura em que as doenças mentais começam a ser reconhecidas como doenças e não apenas um estado mental, e são, portanto, tratadas com acompanhamento profissional e, se necessário, medicação, é importante consciencializarmo-nos que o vício no jogo é de facto uma patologia e o cidadão deve ser devidamente alertado para os perigos do mesmo ("Gambling disorder (GD) has been reclassified recently into the "Substance-Related and Addictive Disorders".) (Menchon 2018)

Assim, decidiu-se desenvolver uma série de cartazes animados com o intuito de explorar a animação como um meio de introduzir uma narrativa adicional ao cartaz, dividindo a atenção do espectador 
em etapas diferentes da comunicação. Inicialmente, apela-se à atenção do observador pelo grafismo. Posteriormente, através do uso de um dispositivo móvel e de uma aplicação dedicada, poderá visualizar uma animação curta relacionada com a mensagem pretendida e, por fim, a mesma é clarificada em forma de texto. Como inspiração para os cartazes, e recorrendo ao conceito de house edge, foi utilizada tipograficamente a expressão "gamblers never win".

\section{O cartaz}

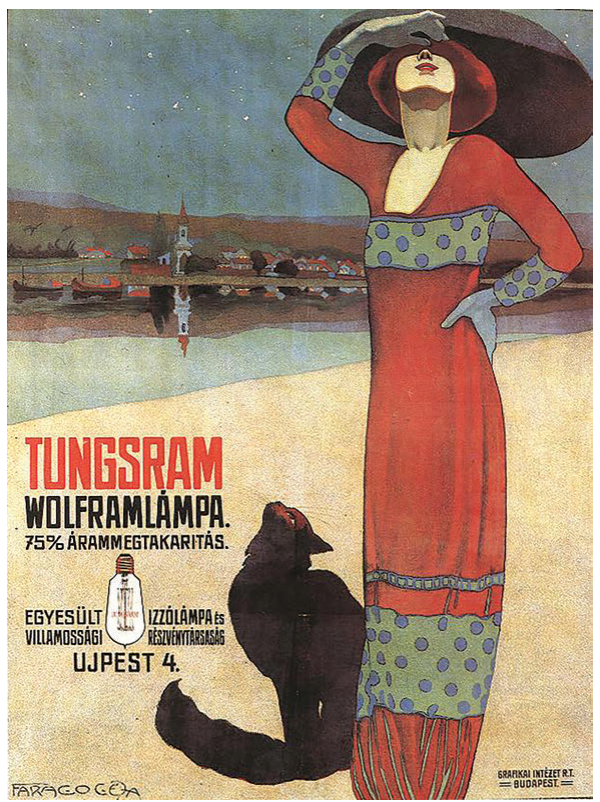

Figura 1 - Cartaz por Faragó Géza publicitando lâmpadas da empresa Tungsram (1910)

O cartaz como meio de transmissão de uma mensagem foi recorrentemente utilizado durante décadas e ainda hoje é utilizado por ser um meio eficaz, abrangente e económico de atingir o públicoalvo de forma rápida e assertiva (Garrigan, 1975). Os cartazes são, por exemplo, uma "ferramenta eficaz e barata para as campanhas eleitorais" (Dezelan e Maksuti 2012, 143). Ao longo dos anos, o cartaz foi evoluindo conforme as inovações tecnológicas e culturais foram permitindo, e hoje é possivelmente um dos suportes e temas mais discutidos do design contemporâneo por permitir, não só pelo seu formato, mas também pela sua expressão, uma plasticidade próxima da pintura e demonstração de inovação e criatividade autoral.

No nosso quotidiano as pessoas são bombardeadas com media impressos (cartazes, flyers, entre outros), que se espalham e ampliam nas paisagens urbanas. Constata-se que as pessoas estão, não raras vezes, ocupadas a olhar e interagir com os seus dispositivos móveis e já não prestam tanta atenção para as paredes onde estão, por norma, colados cartazes em cima de cartazes. Em contrapartida são já utilizados ecrãs de grandes dimensões, ou letreiros em led ou néon, que por vezes até encandeiam os condutores ou qualquer indivíduo que por eles passe. De que forma pode o cartaz aproveitar-se da tecnologia para sobressair neste meio, sem necessitar de ser intrusivo ao nível de prejudicar o bem estar do observador? Este estudo pretende, efetivamente, procurar uma resposta para esta questão.

Unhappily there is a lot of confusion and waste in these messages that surround us. They often weary us with their petulance, their insistence on cramming things we don't want down our throats, and (what is worse) doing it clumsily (Munari 2008, 85)

\section{Animação no design de comunicação}

Quando uma grande percentagem da informação com que lidamos diariamente é transcrita para o meio digital, o conteúdo criado pode e deve aproveitar-se das vantagens disponíveis nesse meio. Uma dessas vantagens é a possibilidade do uso da animação. Desde ícones que representam, por exemplo, que o computador está a processar informação, às páginas inteiras que reagem aos movimentos do cursor, mudando a composição de uma página web através da interação, a animação, introduz a dimensão de tempo e confere ao utilizador a sensação de progresso e dinamismo. Promove-se o feedback, no sentido em que o utilizador pode sentir que está a interagir com uma determinada interface e a mesma está a responder ao seu input.

Num mundo saturado de informação, será mais provável que uma forma diferenciada de comunicar com o utilizador se destaque de formas ditas mais convencionais. A animação parece ser um meio ao qual se vai recorrendo cada vez mais, quer na evolução de interfaces, quer na evolução de estratégias de comunicação.

Um exemplo da utilização da animação na criação de projetos em design gráfico é o estúdio DIA (http://dia.tv/), que utiliza o movimento como uma ferramenta, da mesma forma que o designer utiliza tipografia ou noções de composição, para criar identidades, que acabam por ganhar uma outra dimensão e, consequentemente, destacando-se da concorrência.

Outro exemplo, pela forma como é utilizada a animação no contexto do design é a identidade do "The moving image archive" desenvolvida por Amir Saidani (2017). Nesta identidade é introduzido o logótipo com uma animação que vai repetindo no conteúdo de vídeo associações ao The moving image archive. As deformações no texto são assim atribuídas ao movimento visto na animação mesmo quando a imagem se apresenta estática. 

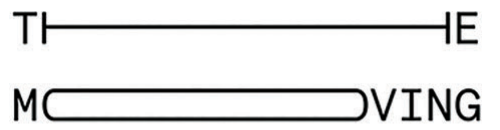

IMAGE

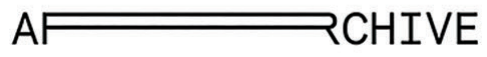

Figura 2 - Logótipo aplicado da identidade do The moving image archive, por Amir Saidani (2018)

\section{O cartaz animado}

A origem do cartaz animado pode ser atribuída à quantidade de ecrãs que vão aparecendo nas paredes das cidades e inclusive nos nossos bolsos ou mochilas. Embora esteja, normalmente, em ecrãs, o objetivo do cartaz animado é o mesmo de um cartaz estático: capturar a atenção da pessoa que passa na rua e rapidamente transmitir-lhe uma mensagem (Schaub 2019).

Josh Schaub, responsável pela criação do movimento "The moving poster" e pelas exposições The moving poster no Weltformat Graphic Design Festival descreve, na sua página web, com o nome do movimento, o cartaz animado como estando entre o cartaz e o filme, e embora seja um cruzamento de ambas as disciplinas, é na mesma um cartaz e a sua principal função deverá ser apelativa, criando interesse, e informativa, transmitindo a mensagem num curto espaço de tempo (Schaub 2019).

Na sua página web Josh Schaub arquiva também vários cartazes que vão ao encontro das normas estabelecidas pelo movimento e apela a que outros autores possam contribuir, enviando os seus cartazes animados, por forma a difundir o conceito e promover o desenvolvimento do cartaz animado.

Tratando-se de um conceito relativamente recente, ainda estão a ser estabelecidas normas e a realizar-se experiências, mas a cada dia que passa o cartaz animado começa a despertar cada vez mais reconhecimento, especialmente com o aparecimento da realidade aumentada. Exemplo disso é o recente projeto e exposição post-print de Serafim Mendes, onde foi utilizada uma mistura de tipografia, cores e grafismo $3 \mathrm{~d}$ e realidade aumentada que permite ao utilizador interagir com os cartazes observando-os de diferentes perspetivas (Mendes 2019).

Nesta área, dos cartazes animados, outros autores de destaque são Marco Oggian com o seu trabalho "posters are better when in motion" (figura 3 ), Syddharth Mate com os seus "kinetic posters" ou Andrei Robu com os posters animados para a fonte Robu Grotesk.

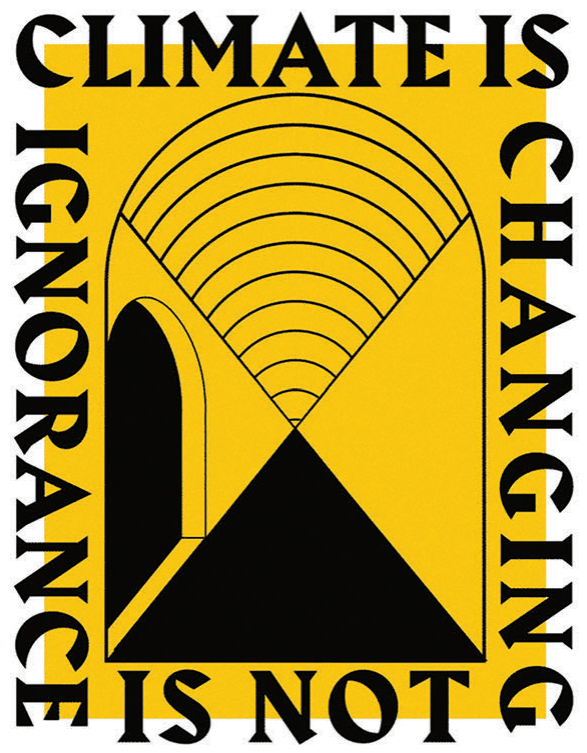

Figura 3 - Cartaz animado da série "posters are better when in motion", Marco Oggian (2018)

\section{Gamblers never win}

Tendo como objetivo criar cartazes com uma narrativa que transmitissem uma mensagem rápida e eficaz, mas memorável para o observador, decidiu-se criar um jogo de formas que brincasse com objetos normalmente atribuídos ao jogo, mas atribuindo-lhes outras características. Através dessa descontextualização numa espécie de trocadilho visual, entrega-se a mensagem num tom humorístico e, posteriormente, desvenda-se um facto sobre o tema abordado no cartaz, demonstrando assim que a imagem surreal apresentada ilustra um problema que na realidade existe.

Decidiu-se atribuir o nome ao projeto de "Gamblers never win" depois de estudada uma tabela que demonstrava, através de um cálculo estatístico que, quantas mais apostas um jogador fizesse, mais dinheiro ele perderia e, eventualmente, será impossível ao jogador recuperar o dinheiro investido, mesmo que tenha uma sorte estatisticamente muito improvável (Bluejay 2018).

Para existir um elo de ligação entre todos os cartazes foi desenvolvido um modelo de animação que faria com que todas as animações tivessem o mesmo ritmo, duração (13 segundos) e as mesmas fases de narrativa. Ou seja, todos os cartazes iniciam com uma moldura que introduz o nome do projeto ("gamblers never win"), procedem a apresentar o trocadilho visual, alteram a composição para revelar o facto relacionado com o trocadilho e retornam à composição inicial para criar um ciclo.

Tipograficamente foi utilizado o tipo de letra 
Twentieth Century desenvolvido pelo designer Sol Hess para a Lanston Monotype, em 1937. As suas características morfológicas, como por exemplo, o facto de se tratar de um tipo de letra sem serifas de inspiração e construção geométricas, permitia uma maior adequação à composição, à disposição dos textos no espaço, tamanho e animação sem comprometer a legibilidade ou adicionar expressão que pudesse interferir em demasia, gerando ruído indesejado. Por outro lado, as formas geométricas desse tipo de letra, pela mistura de linhas retas e curvas, demonstra coerência e compatibilidade com a estética adotada na ilustração dos cartazes, também ela muito simples, num exercício de síntese de valores cromáticos e formais que a aproximam de uma geometrização despida de qualquer decorativismo.

Utilizou-se uma paleta de cores, assim como gradações de cor, de forma a fazer uma aproximação aos cartazes do período Art Deco (há exceção de um dos cartazes). Valores como o luxo e a exuberância foram característicos desse período, estando em consonância e compatibilidade com os valores promovidos por uma instituição como um casino, ao mesmo tempo que criam um contraste entre o conteúdo gráfico do cartaz e o tema abordado. Em cada cartaz existe uma cor que se destaca, em coerência com o tema abordado no mesmo, de forma a tornar evidente que, embora apresentem muitas parecenças, todos se tratam de cartazes diferentes. Desta forma foi também possível criar uma mancha contrastante quando todos os cartazes são expostos lado a lado.

\section{Processo de criação dos cartazes}

Como já se referiu, em cada composição foi escolhido um elemento ligado ao jogo, de forma a criar um trocadilho visual por cartaz. Para isso, efetuou-se um levantamento de vários jogos onde habitualmente se aposta a dinheiro, assim como dos objetos que estavam associados aos mais reconhecidos, de forma a não correr o risco de ser utilizada uma forma que fosse desconhecida para um público fora do mundo dos jogos. Terminado o levantamento desses objetos começou-se por pesquisar as consequências do vício no jogo. Para esta tarefa foram consultados artigos ligado à área da saúde ${ }^{1}$, de onde se elencaram várias consequências associadas ao jogo, como o suicídio, os vícios adjacentes, a depressão, o colapso familiar, a obsessão, entre outros.

Terminada esta etapa procuraram-se ações que ligassem cada problema a um objeto, retirando os mesmos do contexto do jogo e atribuindo-lhes um significado diferente que ilustrasse o tema de cada cartaz. Para isso, cada consequência é expressa por uma ação. O suicídio é representado pelo ato de cortar o pulso; a depressão pelo ato de chorar; e os vícios pelo ato de consumir uma droga. Porém, era necessário decidir quais seriam os objetos escolhidos para essas ações, acabando por se optar por trocar a lâmina que corta o pulso por uma carta, as lágrimas por dados e uma ficha por um comprimido.

Paralelamente a esta pesquisa foram efetuados testes de animação para considerar de que forma poderiam ser representados os movimentos possíveis de encontrar nestes jogos, por exemplo, a rotação de uma roda de roleta, o puxar de uma alavanca de uma slot machine ou movimentos de letras e formas gráficas que, normalmente, se encontram em algumas máquinas de jogo.

Começou-se então a construir a ilustração de cada cartaz num formato $\mathrm{A} 4$, apenas decidindo o esquema cromático quando terminado o desenho. Para o cartaz relacionado com o suicídio foram escolhidos tons vermelhos por estar associado ao sangue, para o da depressão azuis por esta estabelecer uma conexão com a tristeza e para o dos vícios, o laranja por ser uma cor energética e normalmente sinalizadora de perigo (Rikard 2015).

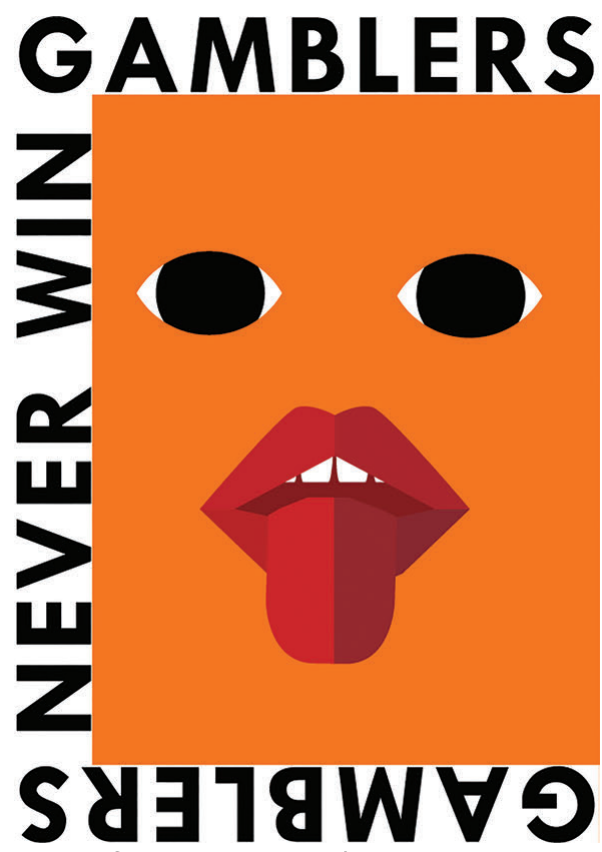

Figura 4 - Cartaz ilustrando que o vício no jogo pode levar a outros vícios 


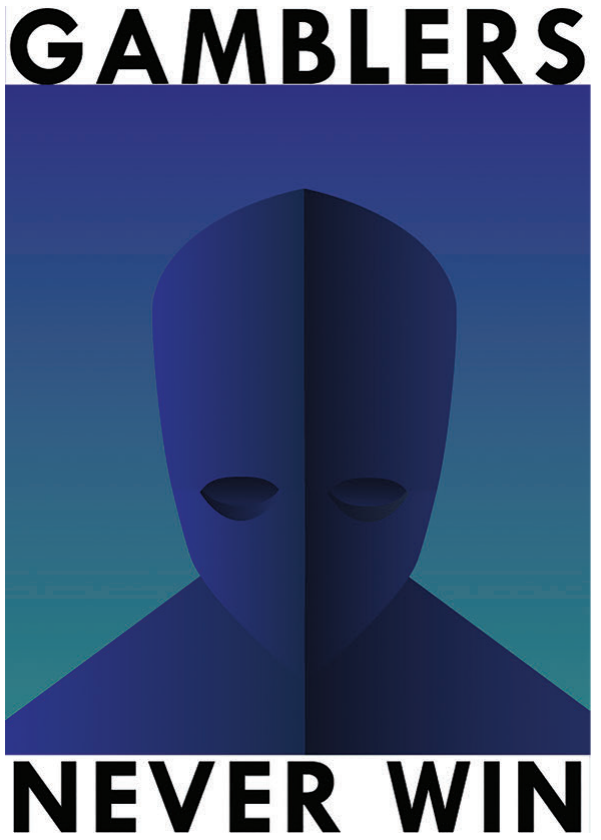

Figura 5 - Cartaz ilustrando a depressão causada pelo vício no jogo

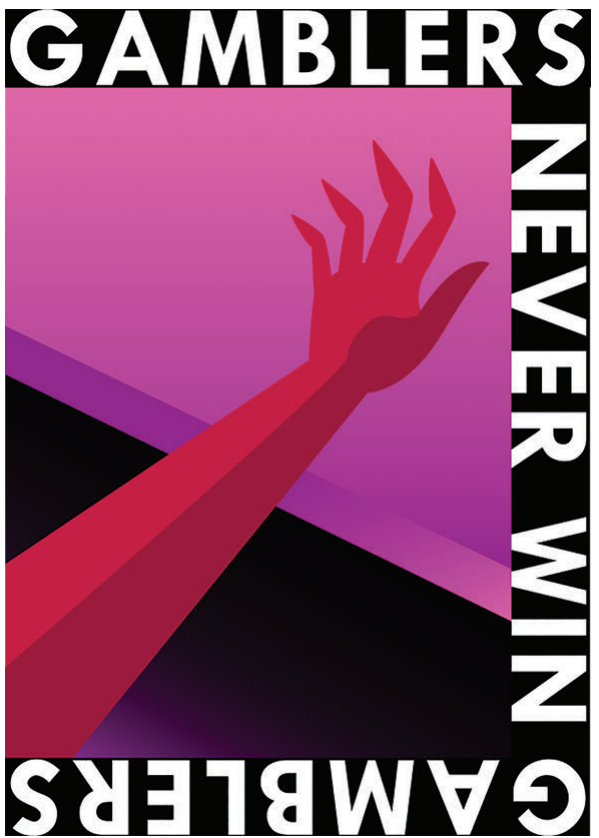

Figura 6 - Cartaz ilustrando a alta taxa de suicídio causado pelo vício no jogo

\section{Exibição do cartaz animado}

No que concerne a expor o cartaz animado, é necessário considerar em que formatos é possível demonstrar a animação criada. Nos meios digitais estes podem, por exemplo, ser difundidos através da internet com ficheiros de vídeo ou em formato gif podendo ser reproduzidos num browser (como os cartazes encontrados na página web do projeto The moving poster), vistos num software de reprodução de vídeo após o download, implementados numa aplicação móvel, entre outras formas de difusão. Se for num espaço controlado, como por exemplo, uma galeria, um projetor pode projetar numa parede através de vídeo mapping. Mas no que toca a demonstrar a animação a um indivíduo que passe por um cartaz na rua, que teoricamente é o meio natural de exibição do cartaz, duas das soluções disponíveis são o uso de ecrãs ou da realidade aumentada.

Os ecrãs, como anteriormente mencionados, já existem em alguns espaços e vão surgindo cada vez mais, nas estações de metro, dentro dos transportes públicos, em alguns desdobráveis, estádios, montras, entre outros. A realidade aumentada não é ainda utilizada, habitualmente, porque implica que o utilizador tenha acesso a um hardware e software que permita o reconhecimento do cartaz através de visão por computador, assim como o acesso a uma base de dados que permita a reprodução do vídeo. Isto implica também que o utilizador tenha acesso à internet, o que já não é um grande problema visto estarem incluídos nos tarifários portugueses pacotes de dados móveis. No entanto, é importante ter em conta que se o utilizador não tiver acesso à internet a única forma do cartaz ser fruído através da realidade aumentada é no caso específico do vídeo estar alojado no dispositivo, o que não se torna tão viável dada a utilização de memória que seria necessária para guardar vários vídeos no dispositivo. Porém, se a aplicação apenas se destinar a um evento em que o utilizador sabe à priori que necessita de uma aplicação para visualizar uma série de cartazes, guardar os vídeos na aplicação pode ser uma opção a ter em conta.

Decidiu-se, mesmo assim, utilizar a realidade aumentada dado o contexto de investigação exploratória que o projeto acarretava. Constatouse que não existe ainda um software de realidade aumentada padronizado, pelo que se recorreu à aplicação Artivive. $\mathrm{O}$ motivo de escolha dessa aplicação recaiu na disponibilidade gratuita de acesso, para efeitos de visualização e submissão (limitada) de conteúdo a qualquer utilizador que tenha acesso a uma loja de aplicações, como a Google Play ou App Store, por exemplo. Esta aplicação faz uso de uma base de dados onde se torna possível associar uma imagem a um vídeo, sendo por isso não exclusiva para cartazes animados, ampliando assim as potencialidades de utilização para outros meios de comunicação ou expressão. 


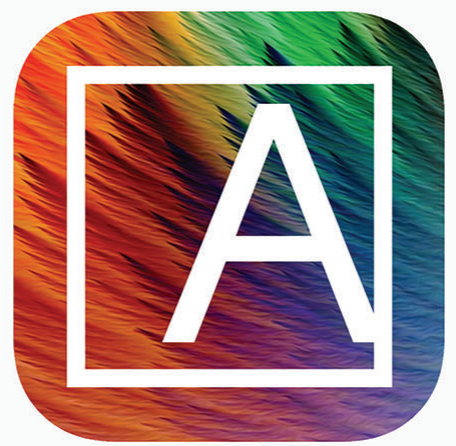

Figura 7 - Ícone atual da aplicação Artivive (2019)

\section{Conclusão}

Durante o processo de criação dos cartazes procurou-se englobar de antemão nas composições, componentes que, posteriormente, pudessem resultar na realidade aumentada, onde o cartaz em movimento adquire realmente outra dimensão. Estes cartazes acabariam por ganhar outro caráter, talvez ainda mais exploratório, se tivessem sido criados recorrendo à tridimensionalidade (3d), num software que permitisse esse tipo de ficheiros, por exemplo. Pensa-se que este poderá ser o próximo passo que se pretenderá levar a cabo num futuro próximo, porque permitiria ampliar ainda mais a interação do utilizador com o cartaz.

Porém, há limitações no uso da tecnologia da realidade aumentada. Existe a problemática de ser necessário um software para usufruir do cartaz animado, que nem todos os públicos poderão adquirir. Tendo em conta a natureza pública do cartaz, parece contra intuitivo, para quem se desloca apressadamente no espaço público, o facto de ter de parar, nem que por breves momentos, para que possa efetuar o download de uma aplicação. Constatou-se também que é prática comum o criador do cartaz animado, especialmente quando pretende utilizar $3 d$, criar também um software associado a esse projeto em específico. Algumas possibilidades que poderiam tornar o cartaz animado mais viável num meio, seriam, por exemplo, os dispositivos móveis como telemóveis ou tablets, incluírem, por definição, um software instalado por defeito que permitisse aceder a uma base de dados de cartazes animados (numa cloud, por exemplo), ou uma aplicação desenvolvida para um espaço, ou conjunto de espaços que fosse acessível e promovida pela comunidade. Outra possibilidade seria uma aplicação para um projeto cultural que alojaria cartazes, numa cloud, de vários autores e locais de forma a expor trabalhos pela cidade e levar o público a interessar-se pelo conceito do cartaz em movimento. Quando aplicação se tornar massivamente instalada e distribuída, o próprio projeto podia colaborar com eventos locais e promovê-los com cartazes animados. Pensa-se que medidas como estas possam tornar a realidade aumentada em cartazes mais presente no nosso quotidiano. Caso se desenvolva outa forma de expor o conteúdo animado do cartaz, sem a obrigação de apontar um dispositivo para o mesmo, talvez o própria função do cartaz estático necessite de ser repensada face a paradigma atual.

Para já o cartaz animado pode deslumbrar nas redes sociais, nos ecrãs publicitários e nas galerias dedicadas a exposições de cartazes, e isso já é razão suficiente para serem desenvolvidos e investigados. Depois de se observar as formas criativas como alguns designers introduziram a animação nos seus cartazes e analisando como os estúdios vão utilizando a animação no desenvolvimento de grafismos publicitários, sente-se que esta é uma época desafiante para os designers. Uma época em que o design e os avanços tecnológicos andam cada vez mais de mãos dadas, influenciando-se mutuamente, ao ponto de permitirem uma evolução tão rápida e ramificada da génese concetual anglosaxónica de design gráfico.

Também é importante salientar que embora existam técnicos para cada meio de criação de conteúdos, o designer deve experimentar o máximo de ferramentas possíveis e contactar com pessoas de outras áreas, quer criativas, como funcionais, de forma a absorver o máximo de conhecimento possível e assim poder inovar e, consequentemente, enriquecer o seu processo de trabalho. Uma colaboração interessante é a da programação aliada à realidade aumentada, podendo utilizar dados alterados em tempo real ou interações físicas como movimentar o cartaz e obter uma resposta por parte do mesmo.

O cartaz animado com uma narrativa, especificamente neste projeto, dada a natureza do mesmo, poderá resultar se exposto na plataforma correta, visto que nas ruas muito possivelmente não chegaria ao público pretendido (devido à limitação imposta pelo software). Talvez a melhor hipótese seria inseri-los nos ecrãs dos próprios casinos, em publicidades promovidas por organizações de saúde (nas redes sociais) ou eventos para a divulgação da patologia em causa.

Isto também levanta a questão que, se um dos melhores meios de divulgação do cartaz animado é a internet, porque não utilizar simplesmente um vídeo promocional onde inclusive se poderá utilizar som para retirar a necessidade dos elementos textuais? Entende-se que o cartaz animado poderá assumir um papel ainda mais relevante do que um vídeo com voice over e imagem real. A tipografia e ilustração animada tendem a ser visualmente mais apelativos do que a imagem real. No caso de um cartaz transmitir uma mensagem rapidamente, após captar a atenção do utilizador, provavelmente a informação irá persistir de forma mais concreta na sua mente por the ter chamado a atenção sem a necessidade de sons intrusivos ou alguma estratégia invasiva utilizada na internet. 


\section{Notas Finais}

1 Northstar Alliance, "Suicide statistics for compulsive gamblers"; Georgia State University, "Depression, suicide and Problem Gambling".

\section{Bibliografia}

Bluejay, Michael. 2018. What is "the house edge"? Vegas Click. https://vegasclick.com/gambling/houseedge Acedido em 3 de maio de 2019.

Dezelan, Tomaz e Maksuti, Alen. 2012. "Slovenian election posters as a medium of political communication: An informative or persuasive campaign tool?" in Communation, Politics \& Culture $n^{\circ} 45$ : 140-159.

DIA studio. 2019. http://dia.tv/ Acedido em 3 de maio de 2019.

Garrigan, John. 1975. Images of an era: The american poster 1945-75. Washington: National Collection of Fine Arts.

Georgia State University. 2010. Depression, suicide and Problem Gambling. http://www2.gsu.edu/ psyjge/Fact/ suicide_04_10.pdf. Acedido em 3 de maio de 2019.

Martine. 2012. História do Casino. CasinoPortugal.com. https://casinoportugal.com/historia/ Acedido em 3 de maio de 2019.

Menchon José. 2018. An overview of gambling disorder: from treatment approaches to risk factors. PMC. https:// www.ncbi.nlm.nih.gov/pmc/articles/PMC5893944/?fbclid= IwAR1v8vFYW3xdCX9qGjIY3ZLNfUL6ZZp9hVI9QCZ6_ YwzeF77ywcVpo4j5KQ. Acedido em 3 de maio de 2019.

Mendes, Serafim. 2019. Post Print. Serafim Mendes. https://www.post-print.com/ Acedido em 3 de maio de 2019.

Munari, Bruno. 2008. Design as art. Londres: Penguin Group.

Northstar Alliance. 2013. Suicide statistics for compulsive gamblers. Northstar Aliance. http:// northstarproblemgambling.org/2013/12/suicide-statisticsfor-compulsive-gamblers/?fbclid=IwAR19Ce3rseAQp6O j48DF02nSPSs6ikD6OrOdXv7upIYIRtpAu12p6TwYB5U. Acedido em 3 de maio de 2019.

Rikard. 2015. The Psychology of Color: A Designer's Guide to Color Association \& Meaning, Zeven Design. https://zevendesign.com/color-association/ Acedido em 3 de maio de 2019.

Saidani, Amir. 2017. The moving image archive. http:// amirsaidani.co.uk/moving-image-archive. Acedido em 3 de maio de 2019.

Schaub, Josh. 2019. The moving Poster. http://www. themovingposter.com/ Acedido em 3 de maio de 2019. 